\title{
A RELAÇÃO PROFESSOR-ESTUDANTE NA EDUCAÇÃO SUPERIOR
}

\author{
Marinalva Lopes Ribeiro ${ }^{1}$ \\ (D) http://orcid.org/0000-0002-9197-1341
}

Resumo: A relação professor-estudante na Educação Superior pode favorecer ou dificultar a rotina e o convívio em sala de aula e, consequentemente, a forma como se dá o processo de ensino-aprendizagem, influenciando a motivação e o comportamento dos graduandos. 0 artigo apresenta resultados de uma pesquisa qualitativa tipo Estado da Arte, na qual mapeamos e discutimos artigos científicos e teses publicadas entre os anos de 2008 e 2018, nos sites Scielo e Google Acadêmico, a partir dos descritores "relação professor-estudante", "relação professor-aluno na universidade", "afetividade no ensino superior". Os estudos analisados revelam diversas situações em torno da relação professor-estudante na Educação Superior. Se por um lado, há profissionais, os quais adotam posturas autoritárias e restritivas que podem influenciar, inclusive, os processos de evasão dos estudantes, por outro lado, a atuação de docentes considerados amigos, humildes e democráticos pode despertar nos acadêmicos o interesse pelos estudos, promover melhorias nas habilidades sociais de tais sujeitos e potencializar suas aprendizagens.

Palavras-chave: Relações interpessoais. Educação superior. Afetividade.

\footnotetext{
1 Doutorado em Educação pela Université de Sherbrooke, Canadá. Pós-Doutorado em Educação pela Universidade do Vale do Rio dos Sinos. Professora Universidade Estadual de Feira de Santana. E-mail: marinalva_biodanza@hotmail.com
} 


\title{
THE TEACHER-STUDENT RELATIONSHIP IN HIGHER EDUCATION
}

\begin{abstract}
The teacher-student relationship in Higher Education can favor or hinder the routine and coexistence in the classroom, and consequently, the way the teachinglearning process takes place, which can influence students motivation and behavior. The article presents the results of a State of the Art qualitative research for which we have mapped and discussed some scientific articles and theses published at Scielo and Google Scholar sites, between the years of 2008 and 2018, with the use of the following searching keys: "teacher-student relationship", "teacher-student relationship at university", and "affectivity in higher education". The analysis has revealed several situations surrounding the teacher-student relationship in Higher Education. If, on the one hand, there are professionals who adopt authoritarian and restrictive attitudes that can influence, even, the students evasion processes, on the other hand, the performance of professors who are considered as friends, humble, and democratic, can awaken in students an interest in studies, promote improvements in their social skills, and enhance their learning.
\end{abstract}

Keywords: Interpersonal relations. Higher education. Affectivity.

\section{LA RELACION PROFESOR-ESTUDIANTE EN LA EDUCACION SUPERIOR}

Resumen: La relación profesor-estudiantes en la Educación Superior puede favorecer o dificultar la rutina y la convivencia en el salón de clases, y consecuentemente , la forma como se da el proceso de enseñanza-aprendizaje, influenciando la motivación y el comportamiento de los graduandos. El articulo presenta resultados de una investigación cualitativa tipo Estado del Arte, en la cual mapeamos y discutimos artículos científicos y tesis publicadas entre los anos 2008 y 2018, en los sites Scielo y Google Académico, a partir de los descriptores "relación profesor-alumno en la universidad", "afectividad en la educación superior". Los estudios analizados revelan diversas situaciones en torno a la relación profesor-estudiante en la Educación Superior. Si por un lado, hay profesionales, los cuales adoptan posturas autoritarias e restrictivas que pueden influenciar, inclusive los procesos de evasión de los estudiantes, por otro lado, la actuación de docentes considerados amigos, humildes e democráticos puede despertar en los académicos el interés por el estudio, promover mejorías en las habilidades sociales de tales sujetos y potencializar sus aprendizajes.

Palabras clave: Relaciones interpersonales. Educación superior. Afectividad 


\section{Introdução}

As nossas relações são permeadas por sentimentos que, dependendo da intensidade das emoções que carregam, nos permitem maior ou menor grau de envolvimento (KIECHOEFEL, 2011). Assim, a afetividade assume participação efetiva na formação do indivíduo, no processo de desenvolvimento e apreensão de seus conhecimentos (PADILHA et al., 2018). Tal importância, obviamente, se estende ao âmbito da educação, já que no campo de ensino-aprendizagem, as relações estabelecidas (especialmente na sala de aula, entre docentes e acadêmicos) favorecem ou geram entraves na rotina e podem ocasionar consequências, tanto para a aprendizagem dos estudantes, quanto para a satisfação dos professores.

Na opinião de Nóvoa (1999), o desafio atribuído aos professores é enorme. É através da relação interpessoal que se cria um cenário pedagógico mais rico e amplo, que melhor responde às necessidades do estudante. Advoga-se que a afetividade e a aprendizagem são intimamente ligadas e influenciadas pela socialização. Desse modo, professor e estudante precisam ser envolvidos e comprometidos para que a aprendizagem ocorra de forma eficaz (KIECHOEFEL, 2011).

Percebe-se que há uma atenção ao papel do professor (ou aos enfoques do processo ensino-aprendizagem) mais direcionada às séries iniciais ou ao Ensino Médio. Todavia, na Educação Superior, as relações afetivas repercutem na vida pessoal e acadêmica dos sujeitos, o que justifica este trabalho investigativo.

Na universidade, o estudante passa por diversos processos que envolvem adaptação, entre eles o estabelecimento de novas amizades, o relacionamento com os colegas, as demandas das atividades acadêmicas, as relações com os professores, as descobertas iniciais do curso e, com o tempo, o condicionamento a ele, a ansiedade e o estresse gerado pelo contexto. A forma como ocorrem as relações com os professores exerce um papel importante e marcante na adaptação e no desenvolvimento dos discentes, visto que a influência daqueles sobre estes não está restrita à transmissão de conhecimentos teóricos e práticos dos conteúdos. Nesse sentido, os docentes universitários são, muitas vezes, vistos como modelos, profissionais em quem se espelhar. Além disso, há uma certa expectativa de alguns estudantes em ter no professor o apoio diante de suas dificuldades de aprendizagem e outras questões particulares ou até um conselheiro a quem possa recorrer nos momentos de conflito. 
0 ensino superior lida com indivíduos que trazem experiências pessoais, valores, interesses e dificuldades particulares, muito diferentes uns dos outros e sujeitos a mudanças. Quando o docente conhece melhor os educandos, pode deixá-los mais à vontade para debater e questionar durante as aulas (ANTÓNIO; MANUEL, 2015). Posto isto, torna-se evidente que as relações positivas, que apresentam simpatia, confiança e respeito, proporcionam um melhor desenvolvimento global da pessoa, porque a possibilidade de bem-estar influencia na aprendizagem cognitiva (PADILHA et al. 2018; SANTOS; MOLON, 2009).

Tendo em vista que tal relação é essencial para qualificar a trajetória universitária e o desenvolvimento da carreira dos estudantes, a interação entre os sujeitos em tela está relacionada ao clima proporcionado pelo professor na sala de aula. Este deve ser pautado na empatia, no diálogo, na capacidade de escutar, perceber as dificuldades e inquietações, compreender, refletir sobre a aprendizagem, rumo a uma convivência mais leve em que se possa estabelecer confiança, reciprocidade e troca de experiências, criando conexões entre o conhecimento, o professor e os estudantes.

A pesquisa de Ribeiro (2010) verificou a insuficiência de estudos dedicados ao domínio afetivo e que a afetividade não se inscrevia como tema de predileção dos especialistas da área de Educação. Diante de tal constatação, nos questionamos como se encontra tal produção na Educação Superior, na atualidade.

Para responder tal questão, realizamos uma pesquisa que está alinhada ao estudo desenvolvido pelo Núcleo de estudos e pesquisas sobre Pedagogia Universitária (NEPPU), do qual fazemos parte. Os resultados deste estudo serão apresentados a seguir. 0 trabalho está dividido em quatro seções. Na primeira, apresentamos o percurso metodológico. Em seguida, exibimos as três categorias organizadas a partir da análise das pesquisas. Por fim, expomos algumas considerações conclusivas e as referências.

\section{0 caminho percorrido nesta pesquisa}

A pesquisa realizada é de delineamento qualitativo do tipo Estado da Arte. De acordo com Romanowski (2002), este tipo de pesquisa requer a definição de descritores para direcionar as buscas, localização dos bancos de pesquisa, estabelecimento de critérios de seleção, levantamento do material, leitura, síntese, organização, análise e elaboração das conclusões. Segundo Ferreira (2002) e Romanowski e Ens (2006), a pesquisa Estado da 
Arte busca mapear e discutir a produção acadêmica na busca de responder quais aspectos e dimensões são destacados em diferentes épocas e lugares, e de que forma tem sido produzidos.

Assim, a partir dos descritores "relação professor-estudante", "relação professoraluno na universidade", "afetividade no ensino superior”, foi realizada uma busca nos sites Scielo e Google Acadêmico, sendo considerados apenas os trabalhos publicados entre os anos 2008 a 2018. Os critérios de exclusão foram as publicações anteriores a 2008 e posteriores a 2018, além daqueles trabalhos que tratavam da relação professor-aluno no âmbito escolar.

Após localizar os trabalhos, foi feita a leitura dos resumos para identificar os objetivos, procedimentos metodológicos e resultados encontrados. Em seguida, os artigos e dissertações foram agrupados de acordo com seus resultados, sendo construído, posteriormente, um quadro com o material selecionado. Após tal organização, foram selecionados 16 trabalhos ao total, sendo 9 localizados especificamente no Scielo e 7 no Google Acadêmico. Em relação ao ano de publicação, 1 foi publicado em 2008, 1 em 2009, 5 foram publicados em 2010, 2 em 2011, 3 em 2012, 1 em 2013, 2 em 2014 e 1 em 2015. Organizamos os trabalhos em 3 dimensões, as quais serão apresentadas e analisadas a seguir:

\section{A importância da afetividade para a aprendizagem}

Os estudos de Veras e Ferreira (2010) mostram que a relação afetiva que se estabelece entre estudantes e professores potencializa uma experiência favorável à aprendizagem. Os autores afirmam que os sentimentos de acolhimento e atenção, bem como as decisões comprometidas com o desenvolvimento dos estudantes, favorecem à compreensão, à aceitação e à valorização do outro, e possibilitam a promoção de uma experiência positiva da aprendizagem.

Nessa mesma linha de raciocínio, Cury (2012) defende que a dimensão afetiva influencia diretamente a aprendizagem dos conhecimentos em sala de aula. Ainda com resultados semelhantes, Jardilino, Amaral e Lima (2010) concluíram, em pesquisa realizada no curso de Administração de Empresas, que além da relação entre a teoria e a prática, a relação positiva entre professor e estudantes contribui efetivamente para a construção da aprendizagem pelos discentes. 
Da mesma maneira, a pesquisa de Santos e Soares (2011), realizada em um curso de Pedagogia de uma universidade pública baiana, mostra que a aprendizagem e a relação que se estabelece entre professores e estudantes estão interligadas.

Diante de tal importância, CAVACA et al. (2010) defendem a valorização dos aspectos relacionados à dimensão afetiva e à cognitiva para se definir uma boa relação. Assim, os acadêmicos esperam que o professor possa extrapolar o discurso científico sem jamais deixá-lo de lado, e considerar as dificuldades de entendimento dos estudantes. Também esperam um tratamento que inclua aspectos que vão além do conteúdo, tais como: a postura, a ética, o respeito, a sensibilidade e outros relativos a necessidades próprias do ser humano (QUADROS et al., 2010).

De acordo com a pesquisa desenvolvida com estudantes de Enfermagem por Semim, Souza e Corrêa (2009), o relacionamento professor-aluno foi facilitado pelo estabelecimento de vínculos. Diversos estudantes afirmam que professores democráticos, flexíveis, com disponibilidade para conversar, esclarecer dúvidas, lidar com a diversidade e que provocam liberdade aos alunos, desenvolvem mais confiança e, consequentemente, um bom relacionamento. Nessa pesquisa, é vista como favorável, a postura do professor que se preocupa com o estudante, com seu aprendizado e até mesmo com sua vida pessoal, não deixando, evidentemente, de exercer seu papel de coordenador do ensinoaprendizagem.

Veras e Ferreira (2010) evidenciaram que a atuação docente despertou nos estudantes 0 interesse em aprender, na medida em que deu retorno àqueles que procuraram cumprir as atividades e participar efetivamente das aulas. Dessa forma, é possível asseverar que as relações estabelecidas na sala de aula podem influenciar na forma como o estudante lida com o estudo de determinado conteúdo, embora existam outros fatores que interfiram nessa questão (CURY, 2012).

Além do exposto, vários trabalhos demonstram que há evidências de maior interesse por disciplinas, cujos professores mantêm com os estudantes uma relação amistosa, demostrando afeição, não sendo agressivos, pois a conduta deles influencia a motivação, a participação e a dedicação aos estudos (RIBEIRO, 2010).

Uma relação na qual uma das partes espera dedicação e envolvimento e a outra espera apenas um tratamento impessoal e profissional, poderá gerar embates no lugar da necessária sintonia. De um lado, o docente - detentor do conhecimento - e do outro, o 
estudante, com objetivos em sua formação que nem sempre são conhecidos pelo professor. 0 não entendimento dos objetivos de cada uma das partes pode levar a interpretações equivocadas e dificultar a aprendizagem (QUADROS et al., 2010).

Em consonância com Santos e Soares (2011), entendemos que a relação professoraluno deve ter como foco, a aprendizagem construtiva do estudante, além de ser baseada na confiança, na disposição e na capacidade de aprender. 0 investimento nessa aprendizagem e o desenvolvimento de uma relação afetiva entre professor e estudante são aspectos do processo formativo que mantêm uma interação dialética e de influência mútua.

Na dimensão interpessoal, em que foram salientadas a paciência e a interação entre professor e aluno, os estudantes esperam que o docente construa um ambiente favorável à aprendizagem. Neste sentido, o diálogo aparece como um aspecto de grande importância na relação entre professor e estudante, já que por meio dele poderá ocorrer a relação horizontal entre docente e discente e a consequente troca de conhecimentos. Assim, ressalta-se a importância da aproximação que não seja "carregada" de formalismos.

O estudo de Possobon (2015) revela que a aproximação entre professor e estudantes possibilita ao aluno retraído por uma eventual timidez, sentir-se mais confortável para compartilhar problemas pessoais, os quais possam estar impedindo a aprendizagem. Também, conversar sobre assuntos diferentes da matéria e, principalmente, tirar dúvidas em relação ao assunto.

Em síntese, as pesquisas analisadas nesta dimensão mostram que as relações entre professores e estudantes influenciam na motivação, na participação ativa, na dedicação aos estudos e, consequentemente, na aprendizagem dos estudantes da Educação Superior.

\section{0 bom professor}

No trabalho desenvolvido por Oliveira (2013), os estudantes ingressantes e concluintes das licenciaturas elegem como características do bom professor: o domínio do conteúdo e sua transmissão, a flexibilidade e a compreensão das dificuldades apresentadas pelo discente. Em contrapartida, o mau professor é visto como aquele que, não tendo desenvolvido habilidades de transmissão do conteúdo, não incentiva o estudante, não dá atenção a ele, não se preocupa com seu aprendizado, nem respeita sua 
produção intelectual. Em síntese, o bom professor é aquele que traz muitas características voltadas para as relações afetivas com os estudantes.

Respostas parecidas foram apresentadas pelos discentes estudados por Candido et al. (2014). Em primeiro lugar, aparece a categoria “é didático” e, na segunda categoria, o bom professor é aquele que "tem bom relacionamento interpessoal" e que interage com os alunos. Além disso, os estudantes demonstraram valorização pelo profissional que tem autoridade para conduzir o processo de ensino, transmitindo conhecimentos da melhor forma possível.

Os graduandos do curso de Direito, investigados por Possobon (2015), informaram como característica do bom professor, ser compreensivo, ter paciência, ser prestativo, acessível, atencioso, aberto a questionamentos, manter um bom relacionamento com os estudantes, ser amigo, simpático, ter carisma e ser democrático em sala de aula, assim como ter a humildade em não se colocar em uma posição de superioridade extremada frente à turma.

Segundo Ventura et al. (2011), tendo em vista que o processo de aprendizagem é favorecido pela relação que se estabelece entre o fazer e a reflexão sobre o fazer, torna-se fundamental ao professor, não só o saber e o saber fazer, mas, sobretudo, o saber ser, e criar um ambiente propício à aprendizagem reflexiva e crítica, a fim de estimular o estudante. Neste sentido, a interação com o professor vai guiar o processo educativo. Dessa forma, para a maioria dos alunos, o processo ensino-aprendizagem é facilitado pelo professor que estimula o pensamento crítico-reflexivo, coerente com a metodologia problematizadora, auxiliando-os em seu desenvolvimento intelectual, encorajando-os a pensar os conteúdos criticamente e motivando-os a caminhar para além do trabalhado em sala de aula (POSSOBON, 2015).

No estudo de Bariani e Pavani (2008), a relação professor-estudante com ênfase no papel comportamental do docente, aparece nas respostas dos estudantes como fator influente na sua participação em sala de aula. Sabe-se que o comportamento do docente como expressão de sentimentos positivos, a oferta de feedback positivo, agradecimentos e pedidos de mudança de comportamento, podem promover melhorias nas habilidades sociais dos alunos (ROCHA; CARRARA, 2011 apud OLIVEIRA et al., 2014). Uma interação baseada nesses comportamentos pode servir como modelo para as futuras relações profissionais estabelecidas pelos discentes (CAVACA et al., 2010). 
Ficou evidente que os discentes valorizam a forma criativa como os professores conduzem as aulas, diferentemente das tradicionais, e principalmente quando há o estímulo à formação crítica e à participação nas aulas. Além disso, os discentes esperam que o professor apresente uma postura favorável à aprendizagem: tranquila, sensível, ética e respeitosa (OLIVEIRA et al., 2014).

A relação pedagógica baseada na construção de vínculos é vista de forma positiva por estudantes do curso de Medicina. Rios e Schraiber (2012) verificaram que os acadêmicos gostavam, admiravam e reconheciam a importância de professores que criavam certo vínculo com eles e com os pacientes, de forma que pudessem inspirar-lhes, para aprender a conversar com os pacientes, a se portar como médicos, particularmente em situações difíceis, como na hora de dar más notícias. 0 acolhimento aos estudantes por eles próprios foi considerado fundamental para o bom desenvolvimento educacional, fator importante, principalmente, para que pudessem ter consideração tanto aos seus afetos envolvidos, como aos dos outros.

Portanto, podemos dizer que a autoestima, a autoimagem e a autorrealização do professor são fatores intervenientes na qualidade do relacionamento estabelecido entre este e seu aluno, o que possivelmente se enlaça à interferência da(s) subjetividade(s) e da(s) cultura(s) dos aprendentes e justifica a intensidade da motivação em aprender (SANTOS; MOLON, 2009).

Em síntese, os trabalhos examinados nesta dimensão apresentam respostas semelhantes no que concerne ao "bom professor", revelando como principais características: não só o domínio, mas a forma de lidar com o conteúdo do componente curricular; a flexibilidade na escuta dos questionamentos dos estudantes; a paciência com eles; a compreensão das dificuldades que os discentes apresentam; o estabelecimento e a manutenção de um bom relacionamento interpessoal com os estudantes. Assim, o bom professor é prestativo, amigo, carismático e simpático; democrático em sala de aula; humilde e simples; respeita a opinião do outro; permite que o discente auxilie no desenvolvimento da aula, opinando e levando contribuições. Por fim, ficou evidente que os estudantes observam os professores, percebem quando estes desenvolvem suas funções com amor e valorizam isso. 


\section{A influência de práticas autoritárias na formação dos estudantes}

Nesta dimensão, analisamos os trabalhos que evidenciam a influência de práticas autoritárias na formação dos estudantes.

Nos estudos de Bardagi e Hutz (2012), ficou evidente o desejo de os professores se preocuparem com a adaptação ao ensino superior e a formação dos graduandos. Neste sentido, estratégias voltadas para a promoção da integração e da aproximação social no início da vida acadêmica podem contribuir para um melhor aproveitamento da experiência universitária, especialmente, em áreas ou cursos em que a formação de vínculos é dificultada pela estrutura e funcionamento acadêmicos, como por exemplo, as áreas técnicas e de exatas. Todavia, nem sempre essa preocupação por parte dos professores universitários acontece.

Os estudantes entrevistados por Bardagi e Hutz (2012), os quais vivenciaram o processo de evasão, revelam percepções de falta de didática por parte dos educadores e ainda, que estes não expressavam paixão pela docência nem apresentavam domínio dos conteúdos, configurando uma situação preocupante, pois os laços estabelecidos com os professores estão associados a sentimentos de satisfação com a universidade, uma vez que possibilitam ao discente um maior envolvimento com a instituição. Se tais laços são enfraquecidos, ou não existem, o envolvimento geral do estudante acaba por ser abalado.

A pesquisa de Bardagi e Hutz (2012) revelou que os estudantes evadidos apresentaram uma avaliação negativa em relação aos professores, considerando seu distanciamento, formalidade excessiva, menor envolvimento com as questões individuais dos acadêmicos, falta de interesse em construir relações pessoais, inclusive, afirmaram ter percebido certa competitividade entre os docentes, a partir das dificuldades de interação e pouca identificação de valores e interesses com os pares. Os participantes destacaram tais aspectos como critérios importantes de desengajamento e evasão. Os relacionamentos, assim, confirmam ser uma parte fundamental da integração e da identificação dos graduandos com o curso.

Nesse sentido, os estudantes consideram negativas algumas práticas como a cobrança de conteúdos que não são explicados em sala de aula, a realização excessiva de seminários nas disciplinas, professores que discutem demasiadamente assuntos que não se referem ao conteúdo, sendo que muitas vezes, alguns deles deixam de se matricular em 
determinados componentes curriculares por causa do professor que irá ministrá-lo (OLIVEIRA et al., 2014).

$\mathrm{Na}$ investigação realizada por Rios e Schraiber (2012), com os estudantes do curso de Medicina, ficou demonstrado que o ambiente de ensino e a atitude dos estudantes dependiam muito do professor. Sendo assim, determinados discentes se comportavam de maneira diferente de acordo com o docente, pois a sua atividade e ou passividade na aula poderia agradar ou, contrariamente, provocar reações negativas no professor que não aceitava uma postura mais interativa. Todavia, o professor exerce o papel de modelo para os acadêmicos. Assim sendo, comportamentos intolerantes dos professores, talvez por acreditarem na ideia da invulnerabilidade do médico que suporta tudo, transparece na atitude de certos alunos, os quais se comportam de forma parecida àqueles professores, tornando-se eles próprios agentes de violência contra colegas e mesmo contra os docentes menos autoritários (RIOS; SCHRAIBER, 2012).

Ainda no estudo de Rios e Schraiber (2012), foi comum a percepção da atitude de ensino centrado no docente como detentor do saber, que fazia a transmissão oral para os estudantes no modelo pergunta-resposta. Na maioria das vezes, o professor fazia a pergunta e ele mesmo respondia. Em diversas situações, os discentes assistiam aulas calados, sem participação ativa; poucas vezes concordavam, questionavam ou discordavam. Para alguns deles, reagir seria falta de educação, de respeito e de capacidade para o ensino. Outros, desde os primeiros anos, se mostraram acomodados com esse lugar passivo (RIOS; SCHRAIBER, 2012).

Na pesquisa realizada por Cavaca et al. (2010), com estudantes e professores do curso de Odontologia, os autores evidenciaram a ocorrência de situações de descuido com o aspecto relacional e até mesmo desrespeito, gerando constrangimentos, como no caso de repressões ao acadêmico diante do paciente, provocando desconforto, algo que pode levar à desmotivação, ao desinteresse pela disciplina, além da repercussão na autoestima, na aprendizagem e na formação geral, visto que as relações instituídas entre professores e acadêmicos servem de guia para as relações que se formarão no futuro entre esses sujeitos (futuros cirurgiões-dentistas) e seus colegas de trabalho, seja da área de saúde ou não, inclusive com seus pacientes.

O trabalho desenvolvido por Cury (2012) destaca, por um lado, a existência de limites rígidos impostos e de distanciamento na relação pedagógica na sala de aula. Mas, por 
outro lado, considerando-se a diversidade existente na universidade, destaca, uma mediação pedagógica que gera aproximações entre graduandos e educadores, possibilitando trocas, a construção coletiva e a coautoria na construção da aprendizagem.

A pesquisa de Oliveira (2013) revela a existência de alguns casos de estudantes, os quais indicaram que a mudança na relação com os docentes deveria partir deles próprios, deixando de ser tímidos, participando mais, dialogando mais com os professores. Mas, há relatos que evidenciam professores com postura inibitória, que não dão espaço para a participação do estudante, revelando práticas autoritárias e restritivas. Evidentemente, tais práticas tornam mais difícil o processo de participação dos discentes.

Os universitários dos cursos de Psicologia e Economia do estudo de Oliveira et al. (2014) relataram que diversos professores agem de forma autoritária e rígida, amedrontando os graduandos. Muitos deles consideraram o descaso aparente, a inacessibilidade e a postura superior de alguns docentes como fatores que podem causar dificuldades na sua transição da Escola Básica para o Ensino Superior. Devido ao consequente distanciamento, diversos acadêmicos não se sentem à vontade para se aproximar e tirar dúvidas junto aos professores.

De tal modo, as relações estão atreladas. Conforme aponta Zuin (2003 apud BARIANI; PAVANI, 2008), quando um estudante é elogiado ou humilhado por um professor diante da turma, não será apenas a relação professor-aluno que estará na pauta, mas, também, as relações dos demais com esse estudante em questão.

A partir do exposto, notamos a importância de os professores atuarem, tanto no nível teórico-didático, quanto no nível interpessoal, mostrando-se abertos ao diálogo e preocupados com a adaptação acadêmica e a formação dos discentes, auxiliando-os na orientação e na carreira (OLIVEIRA et al., 2014).

Em síntese, os estudos analisados nesta dimensão evidenciaram que na universidade, parte dos professores agem de forma autoritária, rígida, impondo limites e repreendendo publicamente os estudantes, muitos dos quais abandonam os componentes por eles ministrados e até mesmo o curso.

\section{Considerações conclusivas}

Os trabalhos analisados apontam que relações professor-estudante hierarquizadas, distantes e autoritárias podem comprometer a aprendizagem, enquanto relações de 
proximidade propiciam condições favoráveis para a troca de opiniões, o interesse e o investimento dos estudantes na aprendizagem dos conteúdos acadêmicos.

Ficou evidenciado que os universitários reconhecem o papel do professor em suas vidas acadêmicas. Para eles, uma relação de proximidade com os docentes, sem que seja necessário abrir mão da autoridade e da hierarquia, incentiva e facilita seu envolvimento com os estudos, com os conteúdos, com a universidade, visto que, além dos conhecimentos cognitivos adquiridos em sala de aula, os conhecimentos da dimensão afetiva são fundamentais na sua formação como futuros profissionais e como pessoas, tendo em vista que determinadas situações marcam e permanecem na memória dos sujeitos, podendo influenciar no comportamento e na personalidade deles.

As dificuldades no relacionamento, marcadas principalmente por excesso de formalidade, autoritarismo, distanciamento, rispidez, falta de interação e menor atenção às questões individuais do discente podem comprometer as expectativas positivas dos educandos, e fazer com que eles se sintam expostos e ou desmotivados para a aprendizagem e até para a continuidade dos seus estudos.

Apesar do evidente direcionamento ao estudo da relação professor-aluno no Ensino Fundamental e Médio, faz-se necessário que o contexto universitário seja investigado, pois a afetividade tem grande importância na Educação Superior, visto que o docente, o qual tem uma competência afetiva na relação educativa, pode criar um clima na sala de aula propício para a aprendizagem. Trata-se, portanto, de um elemento crucial no processo de desenvolvimento dos indivíduos e na relação entre eles, tendo em vista que a postura de professores e de estudantes poderá influenciar na formação e nas atitudes dos outros, como também na relação entre os próprios discentes entre si, e assim refletir no processo ensino-aprendizagem.

Por fim, recomendamos a produção de pesquisas de campo, em que estudantes e professores das diferentes áreas do conhecimento sejam ouvidos sobre as relações que estabelecem na prática educativa. Além disso, reconhecendo a complexidade da profissão de professor, sugerimos o planejamento e a efetivação de programas institucionais de desenvolvimento profissional dos professores universitários, para que possam refletir sobre os dilemas da prática educativa com seus pares e buscar soluções conjuntamente. 


\section{Referências}

ANTÓNIO, L. A. D.; MANUEL, J. A. C. Importância da relação professor - aluno na educação superior. In: EDUCERE Congresso Nacional de Educação, 12., 2015, [Curitiba]. Anais [...]. [Curitiba]: PUCPR, 2015. p. 29888-29897. Disponível em: https://educere.bruc.com.br/arquivo/pdf2015/22201_10845.pdf. Acesso em: 15 out. 2019.

BARDAGI, M. P.; HUTZ, C. S. Rotina acadêmica e relação com colegas e professores: impacto na evasão universitária. PSICO, Porto Alegre, v. 43, n. 2, p. 174-184, abr./jun. 2012. Disponível em:

http://revistaseletronicas.pucrs.br/ojs/index.php/revistapsico/article/view/7870. Acesso em: 18 out. 2019.

BARIANI, I. C. D.; PAVANI, R. Sala de aula na universidade: espaço de relações interpessoais e participação acadêmica. Estud. Psicol., Campinas, v. 25, n. 1, jan./mar. 2008. Disponível em: http://www.scielo.br/scielo.php?pid=S0103166X2008000100007\&script=sci_abstract\&tlng=pt. Acesso em: 18 out. 2019.

CANDIDO, C. M.; ASSIS, M. R.; FERREIRA, N. T.; SOUZA, M. A. A representação social do "bom professor" no ensino superior. Psicol. Soc., Belo Horizonte, v. 26, n. 2, p.356-365, 2014. Disponivel em: http://www.scielo.br/scielo.php?pid=S0102-

71822014000200012\&script=sci_abstract\&tlng=pt. Acesso em: 12 out. 2019.

CAVACA, A. G.; ESPOSTI, C. D. D.; SANTOS-NETO, E. T.; GOMES, M. J. A relação professoraluno no ensino da Odontologia na Universidade Federal do Espirito Santo. Trab. Educ. Saúde, Rio de Janeiro, v. 8, n. 2, jul./out. 2010. Disponível em:

http://www.scielo.br/scielo.php?script=sci_abstract\&pid=S1981-

77462010000200008\&lng=pt\&nrm=iso\&tlng=pt. Acesso em: 12 out. 2019.

CURY, D. G. A relação entre professor e aluno no ensino superior vista por meio da reprovação. 2012. Dissertação (Mestrado em Psicologia Aplicada) - Universidade Federal de Uberlândia, Uberlândia, 2012. Disponível em:

pgpsi.ip.ufu.br/sites/pgpsi.ip.ufu.br/files/Anexos/Bookpage/DissertacaoDanielGoncalve sCury.pdf. Acesso em: 15 out. 2019.

FERREIRA, N. S. A. As pesquisas denominadas "estado da arte”. Educ. Soc., Campinas, v. 23, n. 79, p.257-272, 2002. Disponível em: http://dx.doi.org/10.1590/S010173302002000300013. Acesso em: 19 out. 2019.

JARDILINO, J. R. L.; AMARAL, D. J.; LIMA, D. F. A interação professor-aluno em sala de aula no ensino superior: o curso de administração de empresas. Rev. Diálogo Educ., Curitiba, v. 10, n. 29, p. 101-119, jan./abr. 2010. Disponível em: https://www.researchgate.net/publication/321280268_A_INTERACAO_PROFESSORALUNO_EM_SALA_DE_AULA_NO_ENSINO_SUPERIOR_o_curso_de_administracao_de_ empresas. Acesso em: 18 out. 2019. 
KIECHOEFEL, J. C. As relações afetivas entre professor e aluno. In: CONGRESSO NACIONAL DE EDUCAÇÃO - EDUCERE, 10., 2011, [Curitiba]. Anais [...]. Curitiba: PUCPR, 2011. p. 2533-2543.Disponível em:

https://educere.bruc.com.br/CD2011/pdf/5202_2668.pdf. Acesso em: 15 out. 2019.

NÓVOA, A. Profissão professor. Porto, PT: Porto Editora, 1999.

OLIVEIRA, C. A. V. O que os estudantes universitários pensam sobre seus professores?? um estudo sobre os professores dos cursos de licenciatura do Campus Jataí da Universidade Federal de Goiás. 2013. Dissertação (Doutorado em Educação) - Faculdade de Educação da Universidade de São Paulo, São Paulo, 2013. Disponível em: teses.usp.br/teses/disponiveis/48/48134/tde-13022014120236/publico/CAMILA_ALBERTO_VICENTE_DE_OLIVEIRA.pdf. Acesso em: 12 out. 2019.

OLIVEIRA, C. T.; WILES, J. M.; FIORIN, P. C.; DIAS, A. C. G. Percepções de estudantes universitários sobre a relação professor-aluno. Psicol. Esc. Educ., Maringá, v. 18, n. 2, p. 239-246, maio/ago. 2014. Disponível em: http://dx.doi.org/10.1590/21753539/2014/0182739. Acesso em: 15 out. 2019.

PADILHA, G. L.; OLIVEIRA, A. P. M.; VALOEIS JUNIOR, I. V.; ARAUJO, E. A. S. Interação professor-aluno no processo de ensino-aprendizagem: uma análise de produção cientifica do ensino superior. Rev. Humanidades e Inovação, Palmas, v. 5, n. 3, p. 201205, 2018. Disponível em:

https://revista.unitins.br/index.php/humanidadeseinovacao/article/view/630. Acesso em: 17 out. 2019.

POSSOBON, L. P. S. A percepção do aluno no curso de direito em relação ao bom professor. 143 p. 2015. Dissertação (Mestrado em Educação) - Universidade Estadual do Oeste do Paraná, Cascavel, 2015. Disponível em:

tede.unioeste.br\bitstream\tede $33322 \backslash 5 \backslash$ Lauren_Possodon2015. Acesso em: 14 out. 2019.

QUADROS, A. L. et al. A percepção de professores e estudantes sobre a sala de aula de ensino superior: expectativas e construção de relações no curso de química da UFMG. Ciênc. educ., Bauru, v. 16, n. 1, p. 103-114, 2010. Disponível em: http://dx.doi.org/10.1590/S1516-73132010000100006. Acesso em: 15 out. 2019.

RIBEIRO, M. L. A afetividade na relação educativa. Estudos de Psicologia, Campinas, v. 27, n. 3, jul./set.2010. Disponível em: http://www.scielo.br/scielo.php?pid=S0103166X2010000300012\&script=sci_abstract\&tlng=pt. Acesso em: 15 out. 2019.

RIOS, I. C.; SCHRAIBER, L. B. A relação professor-aluno em medicina - um estudo sobre o conceito pedagógico. Rev. bras. educ. med., Rio de Janeiro, v. 36, n. 3, jul./set. 2012.

Disponível em: http://www.scielo.br/scielo.php?script=sci_arttext\&pid=S010055022012000500004. Acesso em: 17 out. 2019.

ROMANOWSKI, J. P. As licenciaturas no Brasil: um balanço das teses e dissertações dos anos 90. 2002. Tese (Doutorado) - Faculdade de Educação da Universidade de São Paulo, São Paulo, 2002. 
ROMANOWSKI, J. P.; ENS, R. T. As pesquisas denominadas do tipo "estado da arte" em educação. Diálogo Educ., Curitiba, v. 6, n. 19, p. 37-50, set./dez. 2006. Disponível em: http://www.redalyc.orglarticulo.oa?id=189116275004. Acesso em: 15 out. 2019.

SANTOS, B. S.; MOLON, K. S. Reflexões sobre a desmotivação dos estudantes em aprender e as dimensões afetiva, reflexiva e teórica no trabalho docente. Rev. Educação Especial, Santa Maria, v. 22, n. 3, p. 165-180, maio/ago. 2009. Disponível em: http://www.ufsm.br\revistaeducacaoespecialb. Acesso em: 15 out. 2019.

SANTOS, C. P.; SOARES S. R. Aprendizagem e relação professor aluno na universidade: duas faces da mesma moeda. Est. Aval. Educ., São Paulo, v. 22, n. 49, p. 353-370, maio/ago. 2011. Disponível em:

http://www.fcc.org.br/pesquisa/publicacoes/eae/arquivos/1641/1641.pdf. Acesso em: 17 out. 2019.

SEMIM, G. M.; SOUZA, M. C. B. M.; CORRÊA, A. K. Professor como facilitador do processo ensino-aprendizagem: visão dos estudantes de enfermagem. Rev. Gaúcha Enferm., Porto Alegre, v. 30, n. 3, p. 484-491, set. 2009. Disponível em: https://seer.ufrgs.br/RevistaGauchadeEnfermagem/article/view/9210. Acesso em: 17 out. 2019.

VENTURA, M. C. A. A. et al. 0 bom professor - opinião dos estudantes. Rev. Enf. Ref. Coimbra, v. 3, n. 5, dez. 2011. Disponível em: http://www.scielo.mec.pt/scielo.php?script=sci_arttext\&pid=S087402832011000300010. Acesso em: 15 out. 2019.

VERAS, R. S.; FERREIRA, S. P. A. A afetividade na relação professor - aluno e suas implicações na aprendizagem em contexto universitário. Educ. Rev., Curitiba, n. 38, set./dez. 2010. Disponível em:

http://www.scielo.br/scielo.php?script=sci_arttext\&pid=S0104-40602010000300015. Acesso em: 17 out. 2019. 